\title{
Leisure and pleasure: science events in unusual locations
}

\author{
K. Bultitude ${ }^{1^{*}}$, A.M. Sardo ${ }^{2}$ \\ ${ }^{1}$ Department of Science and Technology Studies \\ University College London \\ Gower Street \\ London WC1E 6BT \\ ${ }^{2}$ Science Communication Unit \\ Department of Applied Sciences \\ University of the West of England \\ Coldharbour Lane \\ Bristol BS16 1QY \\ United Kingdom \\ *Corresponding author (karen.bultitude@ucl.ac.uk)
}

Dr Karen Bultitude oversees a wide project portfolio related to methods of engaging public audiences through 'live' interventions. Recent and current research relates to an international review of science festivals; gender-aware teaching in the physical sciences; a comparison of national strategies for science communication; and researcher motivations for becoming involved in public engagement activities. Karen is one of nine national Public Engagement mentors for the Engineering and Physical Sciences Research Council (EPSRC) in the UK and in 2008 was awarded the prestigious Joshua Phillips Memorial Prize for Innovation in Science Engagement.

Dr Ana Margarida Sardo conducted this work whilst a Research Fellow in the Science Communication Unit at the University of the West of England, Bristol. Her research interests include science contributions to environmental policymaking, good practices in communication science and key communication skills in recent graduates. 
Building on concepts relating to informal science education, this work compares science-related activities which successfully engaged public audiences at three different 'generic' locations: a garden festival, a public park, and a music festival. The purpose was to identify what factors contribute to the perceived success of science communication activities occurring within leisure spaces. This paper reports the results of 71 short (2-3 minute) structured interviews with public participants at the events, and 18 structured observations sessions, demonstrating that the events were considered both novel and interesting by the participants. Audience members were found to perceive both educational and affective purposes from the events. Three key elements were identified as contributing to the success of the activities across the three 'generic venues': the informality of the surroundings, the involvement of 'real' scientists, and the opportunity to re-engage participants with scientific concepts outside formal education.

Keywords: informal education, leisure, generic venue

\section{Introduction}

A recent call to arms has been issued to the scientific research and education communities by Falk and Dierking (2010), who emphasise the need to focus more directly on what they call the '95 Percent Solution'. Their suggested approach involves a greater focus on offering opportunities for public groups to engage with scientific concepts outside formal learning environments, in order to improve the public understanding (and appreciation of) science more broadly. Although there are some discrepancies in the wider literature regarding the specific proportion of a person's life that is spent in classrooms (see for example Bransford, 2006 cited in Osborne and Dillon, 2007 or Sosniak, 2001), nonetheless it is incontrovertible that the vast majority of an individual's life is outside of formal learning. Further to this, it has been demonstrated that adults' comprehensions of scientific concepts are derived mainly from activities that they voluntarily choose to 
participate in during their leisure time (Falk, Storksdieck and Dierking, 2007). Learning occurs across an individual's life in a myriad of ways, and not just within the science classroom (Banks et al., 2007; Rennie, 2011), therefore it is important that we take full advantage of wider opportunities to engage public groups.

Such learning is often referred to as 'informal learning', defined as 'all learning that occurs outside the curriculum of formal and non-formal educational institutions and programs' (Schugurensky, 2000:1). In their work for the US National Research Council of the National Academies, Bell, Lewenstein, Shouse and Feder (2009:11) found that informal science learning experiences 'lead to further inquiry, enjoyment, and a sense that science learning can be personally relevant and rewarding'. In terms of the identified benefits of such approaches, McCallie et al. $(2009: 53,32)$ emphasise outcomes from informal learning experiences such as "bringing meaning and richness to the lives of publics' and helping people to 'see themselves as empowered, valuable, integral parts of their communities and society'. Furthermore, placing such activities within relaxed environments that are familiar to the participant, and incorporate some form of entertainment value, can promote a willingness to learn and the continuation of learning (MacDonald, 2004). There is thus evidence that opportunities to encounter science in an informal context lead to both immediate positive outcomes, as well as potentially improving participants' attitudes towards future learning.

\section{Impacts of venue choice}

The selection of an appropriate location is a critical aspect in any science communication activity, whether it be in an informal context or not. Within the US it has 
been shown that adults specifically associate science with a university or laboratory (Gauchat, in press), and this is understandably an assumption that is difficult to overcome. For public engagement purposes, taking science out of the laboratory and into more 'public' spaces can have a powerful effect. Within Europe these benefits are recognised to the extent that a European-wide membership organisation exists to share common practice. The European Science Events Association (EUSEA) is committed to events 'going out to the people, thereby reaching a different audience ... namely these persons, who might not 'dare' to enter scientific venues' (EUSCEA, 2008:1).

Within the literature the effect of venue choice has been explored most prominently in the context of consensus conferences and other consultative processes. For example, it has been identified that using a meeting location which is neutral and nonthreatening for all participants is crucial to ensuring fair and equal involvement (Cherryman, King, Hawkes, Dinsdale and Hawkes, 2008), and that the use of an 'exclusive' venue can have a recognisably negative effect by creating a 'forbidding' atmosphere which is 'not conducive to discussion' (Schibeci and Harwood, 2007:250). Whilst less researched, these issues are arguably just as crucial in more informal environments.

The places where informal learning occurs have been divided by Bell et al. (2009:2) into three main categories: 'everyday experiences', 'designed settings' and 'programs'. Previous research (see for example Dabney et al., in press) has focused mainly on events in designed settings (where public groups actively choose to visit a specific venue, such as a science museum) and programs (which include after-school as well as community activities). In both of these environments participants have pre- 
existing expectations that they will encounter science in some way, even if their motivations for attending are not purely educational (see for example Falk, 2006). However, less research has been conducted to date on participant experiences in ‘everyday’ venues, especially at an over-arching level (as opposed to investigating discrete events in isolation). In light of the importance of everyday and informal experiences in science learning, this article compares the findings across three case study science communication activities that took place within locations designed primarily for leisure activities. Specifically, this work isolates experiences at leisure venues (which the participants have actively chosen to visit, but not for reasons related to science) from more habitual interactions (such as in the home or workplace) in order to further explore the interface between the 'everyday' and the 'designed settings' described above.

\section{Leisure and 'Generic Venues'}

Within the wider field of leisure studies there are three distinct ways of defining leisure that have emerged (Edginton and Chen, 2008). 'Leisure time' corresponds to specific periods spent according to personal taste and inclination (as opposed to maintaining basic bodily existence or within study/employment). Alternatively, leisure can be defined by the type of activity involved - what does the individual do within that (unpaid) activity that separates it from other parts of their life, be it a hobby, sport, social occasion or creative pursuit? A third, more nuanced, approach focuses on the individual's state of mind or attitude, based around the recognition that:

...most leisure experiences occur in casual, social occasions. In other words, leisure often occurs when one is informally engaging others, physical, or abstract objects and even in dialogue with oneself however briefly. This can be contrasted with the more exotic, highly organized forms of leisure, such as organized sports, 
concerts, community special events, art shows, or other venues. (Edginton and Chen, 2008: 8)

There are clear connections between this perspective of leisure and the informal learning context described previously, especially in terms of the distinctions between highly organised activities (such as informal science learning programs and many designed settings) and casual, social occasions (which are more akin to 'everyday' informal learning environments). Furthermore, certain relevant characteristics have been proposed for recognising when an individual is mentally 'at leisure', for example whether they were free to choose to participate and whether the leisure forms were 'physically active, pleasurable, relaxing or creative' (Bull, Hoose and Weed, 2003: 35). The element of choice is of course overtly recognised within informal learning through Falk's preferred term of 'free choice learning' (Falk, Donovan and Woods, 2001). It is however important to note that although their choice of leisure activity is overtly up to the individual concerned, there are subconscious factors at play that influence those choices. Family or peer influences, education and social backgrounds, and even basic elements such as their physical location can all contribute to where individuals choose to spend their leisure time (Bull et al., 2003:57 citing Haywood et al., 1995). This means that for some sectors of society it is highly unlikely that they will participate in designed settings for informal science learning, thus to engage those groups it is crucial to encourage greater opportunities within appropriate everyday environments.

Combining the above concepts of the importance of venue selection and reaching public groups when they are 'at their leisure' leads to the notion of a 'generic venue' as a location for informal science learning. Within venues such as parks, bars, cafés and 
festivals publics naturally congregate for casual, social occasions, and such groups may then unexpectedly engage with scientific concepts in an informal manner via externally organised activities. Such generic venues differ from 'designed settings' such as museums or aquaria in that the visitors involved do not expect to encounter science at that location; the settings are often already familiar to the audiences involved and constitute a neutral meeting point between science and publics. Thus successful activities within generic venues aim to exploit the element of surprise and novelty in finding science in such locations, and build on the relaxed and social nature of the leisure environment in which they occur.

\section{Previous research in generic venues}

Academic research in generic venues has to date focused mainly on reviewing individual events from a simple evaluative perspective. Whilst innumerable summative reports no doubt exist regarding such events, forming an overarching perspective of learning from such events is further hampered by the fact that very few such reports are currently available in the public domain. This section summarises the key reports that are available, although the authors recognise that other learning may have occurred outside of an academic context.

Recognised generic locations used as venues include 'pubs, post offices and garden centres' (Johnson and Burnet, 2000:16). Furthermore, a popular example of a well-recognised science communication activity in a generic venue, which may be found all over the world, is a Café Scientifique (also known as a Science Café or SciBar or similar). These informal discussion events take place in cafés, bars and restaurants. The 
success of the Café Scientifique is in its simple concept: members of the public have the opportunity to discuss science in a relaxing and informal environment (Grand, 2009). Cafés Scientifique are however usually pre-arranged, with audience members specifically choosing in advance to attend the event. There have been other bespoke science events reported in leisure venues, for example a science party (Koolstra, 2008) and a biomedical public engagement project, which included exhibitors and speakers from the University of Leeds (Ward, Howdle and Hamer, 2008), however this work focuses on events where the majority of the audience have no premeditated intention of interacting with scientific content. An internationally relevant example is the poster exhibition From Earth to the Universe (FETTU) that was developed to celebrate the International Year of Astronomy (2009). It was displayed in locations all over the world and brought 'astronomical images and their science to the public in non-traditional locations such as public parks, metro stations, shopping malls, hospitals, libraries, and even prisons' (Arcand and Watzke, 2010:1). The authors concluded from the FETTU evaluation that 'exposure to scientific content in these settings leads to inspiration and small learning gains' and that 'different location types ... can have an impact on visitor engagement' (Arcand and Watzke, 2010:78) although they did not comment on exactly what features of the locations created impacts on the visitors.

Science communication initiatives have even taken place in locations where people are travelling between venues. Over a decade ago Science on the Underground used posters on the London Underground to 'raise interest and awareness, provoke follow-up action and raise the understanding of science amongst passengers' as they made their journeys (Naylor and Keogh, 1999:105). This was achieved by combining concept 
cartoons with science-based questions, thereby enabling the passengers to encounter the scientific concepts in an unexpected manner in a location that was familiar to them. This approach succeeded in reaching a broad sample of passengers, not only those who were scientifically literate (Naylor and Keogh, 1999). Buses have also been utilised as generic venues: Science on the Buses, a poster campaign on buses in different parts of the UK demonstrated that the audience was more likely to consider science a part of their own life in the context of the posters (Johnson and Burnet, 2000). An extended version, SciBus, ran simultaneously in 15 cities across Europe in 2002, reaching a potential audience of 25 million people in twelve languages and incorporating what was (at the time) the novel approach of encouraging participants to submit their personal responses via text message (Johnson, Burnet and Pichler, 2003). Through this approach SciBus became more than a standard advertising campaign and made an effort to incorporate a more consultative element in line with Rowe and Frewer's (2000) typography of public participation methods.

Generic venues therefore offer strong potential for informal science engagement, however over-arching evidence is currently lacking regarding what attracts participants to those activities, and what specific aspects create positive impacts on the participants. This paper seeks to provide insights that will assist in the planning and development of future activities in generic locations.

\section{The case studies}

The present study compares data from three contrasting generic venue types: a garden festival, a city park and a music festival. For cultural and temporal coherency the case 
studies were all sourced from within one country (England) and within a single year $(2009 / 10)$. The chosen case study locations were anticipated to reflect a wide range of audiences and involved a diverse range of venue facilities. All three venues involved places where non-specialist members of the public were likely to be present due to their own inclinations and interests. Whilst this is almost certainly not the first time that such activities have occurred in similar venues, it is the first time that a comparison has been made across them for research purposes.

Physics in the Field at the Holker Garden Festival, Cumbria (HGF): This annual festival is a celebration of the countryside, gardens and food and attracts mainly a family audience. Physics in the Field involves members and staff from the Institute of Physics performing physics demonstrations to engage families and children. The activities consist of small scale, simple and entertaining demonstrations that the festival participants try for themselves. Each helps to illustrate an area of physics. The venue was located in a rural area that is popular with tourists in the north west of England over a three-day period.

BioBlitz at the Ashton Court Estate, Bristol (ACE): During a BioBlitz scientists and volunteers conduct a biological survey over a specified time period (usually 24-48 hours), attempting to identify and record all species of living organisms in a given area. This particular BioBlitz took place at the Ashton Court Estate, a historic country park in the south west of England. This venue was located in a large park close to an urban area with an overall duration of 30 hours.

Guerilla Science at the Latitude Festival, Suffolk (LF): Latitude is an annual music festival that includes not only music but also elements of theatre, art, comedy, poetry, politics and literature. Guerilla Science is an independent group of young science 
communicators who are committed to taking science to music festivals through talks, workshops, demonstrations and live experiments. This event was held over three days, with activities taking place mainly during late afternoon/evening.

The study reported here investigated the public's perceptions of science-related activities taking place in generic, non-traditional venues. Specifically, the authors sought to understand:

(1) What types of participants were attracted to science-related activities in generic venues, and what factors contributed to their choice to become involved?

(2) What are the experiences of participants who get involved in the activities?

(3) What are the participants' perceptions of the purpose(s) of the activities?

\section{Methods}

A variety of evaluation methods were exploited at generic venue locations in order to determine which were most appropriate for use with informal science activities in leisure environments. As emphasised by Allen (2008:31), it is 'important that participants not be traumatized or alienated because of over-zealous assessment practices (which would also lessen validity of the results)'. For this reason, the methods chosen were designed to minimise the amount of disruption and interference on the part of the participants, so that an atmosphere of relaxation could be maintained. Whilst the three case study venues were specifically chosen in order to represent a contrasting sample, the same evaluation challenges were present at all three venues. These challenges included encouraging recruitment, minimising interruption to the participants, and avoiding overly 
'formal' techniques that would be at odds with the activities involved. For consistency the same complementary evaluation approaches were therefore used at all three venues.

Structured interviews were judged to be an appropriate method since they enabled the research team to directly access the observations, insights and the experiences of the participants themselves (Tong, Sainsbury and Craig, 2007). As previously identified by DeWitt (2009), a short duration and a highly structured approach proved most successful in recruiting potential participants. In the case of the generic venues investigated here, an interview duration of 2-3 minutes proved optimal. This length of time was short enough to create minimal disruption to audience members during their leisure activities, thereby ensuring sufficient participation at each venue whilst still collecting useful information for the purposes of the research.

The researchers were however concerned about potential interview bias created through the face-to-face contact with all the participants (David and Sutton, 2004). For this reason, other methods (e.g. written exit questionnaires) were trialled during the early stages of this research. However, low response rates in the chosen environments meant that these methods proved not viable for research purposes. This was not entirely unanticipated: during similar activities reported from a physics-related stand at Glastonbury Festival (a large scale popular music event held within south west England), it was noted that only six comment cards were completed by participants over four days, with the final report noting that 'this was not an easy way to collect information at such an event, possibly since the Festival atmosphere is much more geared to stimulating the senses (particularly listening and talking) rather than reading and writing' (Bultitude and Grant, 2005:18). 
A complementary approach that did work was the combination of periodic structured observations to support the data gained from the interviews. Similar research methods were used by Naylor and Keogh (1999), who combined structured interviews and observations in order to evaluate the project Science on the Underground. At the three generic locations studied here, the researcher present took extensive contemporaneous notes on the size, composition and visible reactions of the audience during their participation in the activities. This enabled participants' responses from the interviews to be compared with their reactions during the events themselves.

Further details on the approaches used within both the structured interviews and the observations are provided below. Prior to data collection all methods and subsequent data storage, analysis and reporting procedures were subject to review by the [institutional affiliation removed in order to retain anonymity] ethics and research governance committee.

\section{Structured interviews}

Short structured interviews were used to ascertain participants' reactions across the three case study events. Since the researchers did not wish to daunt participants who were less familiar with science, the interview questions were designed to be brief, clear and simple (Naylor and Keogh, 1999). In total, 71 people were involved in structured interviews conducted across all three venues, with a mixture of adults and children involved.

A unique anonymous identifier was allocated at the start of each interview in order to enable each interview to be distinguished during transcription, analysis and reporting. 
The interview schedule consisted of six core questions and was designed to last for 2-3 minutes in duration as outlined above. The questions focused on participants' reasons for getting involved in the activity, what they perceived its purpose to be, and their affective reactions to it:

- What attracted you to this activity?

- What was your favourite aspect of the activity?

- What was your least favourite aspect of the activity?

- What do you think the purpose of the activity was?

- Would you like to participate in this sort of event again in the future?

The participants' general attitude towards science was also probed in order to provide a baseline comparison for their comments:

- Personally, how do you feel about science generally?

Finally, for demographic purposes the participant's gender was noted and their age (if under 16; marked as 'adult' otherwise).

The use of open-ended questions allowed participants to supply their answers using their own terminology (David and Sutton, 2004) and was chosen in order to produce useful information as well as unanticipated responses. For consistency one researcher ( [initials removed in order to retain anonymity] conducted all the interviews, which took place with audience members in person, as participants were exiting the activities. Each interview was audio-recorded after receiving verbal consent from the respondent. Due to the flexible and generalised nature of the questions the same interview schedule was used for all three case study venues. 
Participants in this study were selected for maximum diversity by as many characteristics as possible (including their age, gender and the type of group they were attending with e.g. entirely adults or as an inter-generational family etc.). As with previous work investigating public opinions, this choice of sampling was 'not because we thought these individuals would be representative of other people with similar backgrounds ... but to maximize the potential diversity of perspectives brought to bear' Powell and Kleinman (2008:338). A further criterion for choosing interviewees was that participants must have been actively involved with the activities for a minimum of five minutes.

\section{Observations}

In addition to the interviews, structured observations were conducted for 15 minute periods spaced regularly throughout the entire duration of the events (Bentley, Boot, Gittelsohn and Stallings, 1994). During these observations, notes were taken on the reactions of participants and audience to the activities, as well as on the number and composition of the audience. As with the structured interviews, to ensure consistency one researcher ( [initials removed in order to retain anonymity] took responsibility for completing the observations. The researcher was situated in an unobtrusive location and recorded data such as:

- Staff delivering the activities: (rough) age, appearance, confidence, enthusiasm;

- Audience: type (multi-generational, couples, etc.) and size of groups, (rough) age ranges and genders; 
- Group dynamics: do members of the audience work together or as individuals? Do they talk with each other about the activities?

- Engagement: how are the audience attracted to the stall, are they actively involved or just observing, etc.?;

- Dwell time: how long did the audience stay for?

Observations were timed to include both the early stages of activity delivery as well as particularly busy times. Across all the evaluated events there was a natural flow to visitor levels and participation across the duration of the events, therefore running observations at different times meant the broadest range of involvement could be observed. The timing of the observations also ensured that children as well as adults were represented in the data collection.

In total, 18 observation sessions were made throughout the events: nine over the three days of the Holker Garden Festival; five over the course of the 30 hour Bioblitz; and four during the three late afternoon / evening sessions at the Latitude Festival. The different numbers of observations at each case study venue reflect variations in the opportunities available for conducting the observations. At HGF the event involved dropin activities throughout the three days with a roughly consistent level of audience involvement, therefore there was more flexibility in deciding when observations could be taken. ACE likewise involved a relatively stable number of participants (at least during daylight hours when observations could be conducted). In contrast, at LF the events were generally concentrated at specific (advertised) times, therefore audience participation tended to involve larger numbers of people focused over shorter time intervals. Indeed, at LF there were multiple occasions where the audience size and degree of interaction was 
too large to allow for robust observation by a single researcher using the categories of interest described above, and data collection using that method had to be abandoned. Due to these inconsistencies observation data are not presented in depth within this article; instead they are used purely to provide context for existing data from the participant interviews.

\section{Analysis}

The interviews were audio recorded and transcribed. The qualitative software program NVivo was used to code and analyse the transcripts, from which common themes were identified, both on an event-by-event basis and also across all three case studies included in this research. Emergent themes were sorted into excerpt files to locate patterns in the audiences' perspectives of science communication activities in generic venues. The coding frame was developed following the five-step framework analysis developed by Ritchie and Spencer (1994). Comparing and relating the resultant themes (Bazeley, 2009) produced key findings which are discussed in turn in the following section.

\section{Results and Discussion}

Detailed analysis of the interview transcripts reflects extremely positive reactions of the audience members to the science-related activities held at the three generic venues. In line with previous similar work (see for example Brehaut and Simonsson, 2006; Ward et al., 2008), many interviewees commented favourably (and expressing some surprise) at how simple, easy to understand, and accessible the science was, and the likely impacts of 
such an approach on their own or others' learning and/or interest. The audience participation opportunities and hands-on nature of some activities and were also key highlights mentioned by participants.

Affective enjoyment through the participants' having 'fun' was also an important factor and was mentioned several times during the interviews. During the observations a large number of participants were smiling and laughing while engaging with the activities, and displaying other visible signs of enjoyment. This short-term enjoyment is likely to have longer-term consequences: as Packer (2006:340) concludes in the context of learning for fun, 'although most visitors don't come with a deliberate intention to learn, they do seek or are unconsciously drawn into an experience that incorporates learning'. While Packer was referring to activities in designed settings such as a visit to a museum, zoo or aquarium, the evidence from this work is that the same is also true for activities held in generic venues.

As noted above, the 71 interviews conducted during this research were very short - each no more than three minutes in duration. It is therefore not possible to ascertain indepth perspectives; nevertheless, key themes do emerge. In line with the focus on 'generic venues' as possible locations for recruiting publics to everyday informal learning experiences, this discussion will focus on three key emergent factors:

- Backgrounds: who was attracted to the activities?

- Motivations: why did those participants become involved?

- Perceived purposes: what purposes did the participants perceive for such activities? 
For the benefit of practitioners interested in delivering events in generic venues a brief synopsis is also provided regarding what factors contributed to the activities' success.

\section{Participant Backgrounds}

Details on the number of interviews per venue (including gender and age breakdown) are provided in Table 1. An indication of the overall number of participants at each event (supplied by the activity organisers) is also provided for comparison.

[Insert Table 1 about here. Caption: Demographics of the interview participants at each case study event]

With the exception of the Latitude Festival (which aimed specifically at an older audience), both adults and children (defined as participants under 16 years old) were involved in the interviews. Although no data were able to be collected relating to socioeconomic status of the participants, it is likely that few participants came from the lowest socio-economic groups. At each of the selected venues there was some form of financial barrier in place: admission charges applied at both HGF and LF, and all three venues required pre-organised transport due to their distance from residential areas. The venues did however all fall firmly into the category of 'leisure' attractions, therefore were seen as good testbeds for potentially involving people not normally interested in science. Due to the informal nature of the events, and the emphasis on keeping the atmosphere relaxed and enjoyable without intruding on the participants' leisure time more detailed demographic data were not sought.

Within the interviewee participants, 60 were able to provide a relatively clear indication of their existing attitudes towards science (with the remainder claiming to be 'unsure' or not explicitly answering the question). Attitudes were generally fairly 
positive: $28 \%(\mathrm{n}=17)$ of the interviewees described themselves as being 'interested' in science, whilst $20 \%(\mathrm{n}=12)$ stated they 'liked' the subject and a further $7 \%(\mathrm{n}=4)$ claimed to 'love' science. In particular, it was more common amongst participants at HGF to express personal positive feelings about science: 12 of the 16 respondents who stated they either 'liked' or 'loved' science came from that venue, although there was no observable trend according to gender or age. This result may have been influenced by (negative) peer pressure or (positive) family expectation factors: at ACE and LF most participants were attending with their friends and/or peers, whereas at HGF the majority of participants were in family groups.

A further $35 \%(n=21)$ of respondents provided other positive comments about science more broadly, for example that it was 'important' $(\mathrm{n}=5)$ or inspired reactions such as fascination, enjoyment, excitement or amazement. Not all of the participants were proscience however: $5 \%(n=3)$ expressed neutral opinions and a further 5\% $(n=3)$ actively claimed to 'dislike' science. The overarching positive reported attitudes may reflect an element of interview bias, where the participants gave responses they thought the interviewer wanted to hear, thereby reflecting more positive opinions towards science than was actually the case. However, these findings are broadly in accordance with studies of public attitudes to science within the UK at around the time the research was conducted: in 2008 it was identified that $82 \%$ of the non-specialist public were 'amazed' by science, whilst $12 \%$ indicated that they were not particularly interested in science and science issues (RCUK/DIUS, 2008). The similarity between the results therefore suggests that the participants were roughly representative of the wider UK population. 


\section{Motivations for involvement}

Across the three events the interviewees expressed a variety of motivations for participating in the activities. Just under a third of the participants interviewed $(\mathrm{n}=22$, $31 \%$ ) stated that they had come to that particular activity deliberately, either because they had seen some advertising at the event itself (e.g. a description in the wider event programme or on an information board) or they had heard about it in advance on local TV/radio. This indicates that just over two-thirds (69\%) of the audience members may have become unexpectedly involved in the activities. Ten participants explicitly indicated that they had just been 'passing by', whilst a further 13 participants provided implicit evidence of the generic nature of the venue facilitating their science interaction (for example referring to looking for something to 'entertain the kids'). HGF was particularly successful in attracting participants who had not otherwise planned to participate in a science activity: only two (of 34 people interviewed there) were aware of the activities in advance. The nature of the HGF venue and associated activities are the most likely contributors to this success: the science stall at HGF was one component of a much larger event, and the activities were specifically designed for relatively short drop-in sessions. Conversely, at ACE the venue was relatively remote, resulting in lower visitor footfall more generally, and a greater reliance on pre-arranged participants. At LF the longer duration of the activities (for example short lectures and discussion sessions), combined with relatively limited space availability, created a barrier to wider participation. Indeed, some participants at LF reported developing strategies to ensure that they were able to get into specific sessions:

Actually I wanted to come to the next talk, but I came to the one before because it was a good way to get to the next one. (LF3, male adult) 
Whilst all potential participants may not display such dedication, it is certainly a positive sign for informal science learning that the science-related activities at a popular music festival resulted in the available space being full to capacity.

Returning to the reported experiences of those who became involved after passing by, these participants were in the vicinity for external reasons associated with their leisure pursuits at that venue, and were attracted to the activities because the stand looked 'bright and colourful', or involved appealing activities. The fact that there was a crowd of people and that they looked excited and were making noise also attracted visitors:

I just saw exhibits and children around being interested and I could see there was an activity and having an enquiring mind, I said 'what is going on there?' (HGF11, male adult)

Because it looked interesting and we have seen people crowding around here and heard a woman screaming at something that happened. (HGF9, female child)

Use of brightly coloured and highly visible props (such as balloons) was also reported to attract people to activities. Moreover, logistical considerations played a part: one person was driven into the event marquee by the rain outside. Other aspects that initially attracted the audience (particularly children) to the activities included the hands-on and interactive nature of the tasks on offer. In addition, in line with previous work (Brehaut and Simonsson, 2006), the novel and unexpected nature of the activities in the venues in question was an identified factor in recruiting audiences, particularly in the case of adults.

Even in generic and informal venues such as the ones reported here, the fact that the activities were about science seemed to have attracted some members of the public. 15 interviewees specifically made reference to the scientific content as being an aspect that 
attracted them to the stall. These 15 participants came from a diverse range of backgrounds: both adults and children, and including those with and without a stated preexisting interest in science. In many ways this result suggests that running science activities in generic venues succeeds well in attracting those who already have the potential to seek out scientific experiences, rather than the wider public groups alluded to in the introduction. It is probable however that participants without an existing interest in science also became involved. The aforementioned sample represents just over $21 \%$ of the interviewees, suggesting that for the majority there are other factors (not relating to a preexisting interest in science) that encourage their involvement. Secondly, as noted above, the participants may have been trying to provide the interviewer with what they perceived to be the 'right' answers to this question. After having participated in overtly sciencerelated activities they may have felt it was preferable to exhibit greater interest in and/or association with science than may have been true normally. Future research investigating the reactions of participants to less overtly 'scientific' activities in generic venues, or alternative research methods for this element (such as anonymised voting scales or similar) may help to clarify the extent of such interviewer bias.

In line with the family-oriented nature of HGF and ACE, many adults present at those venues associated their involvement with encouraging learning or enjoyment in others, particularly their children:

My husband, he is very into physics he likes that kind of stuff and wanted to show it to our daughters. (HGF3, female adult)

I think it's important to point it out to the children and to see what is going on. (ACE10, female adult) 
In addition to such vocal comments, when children were present the researcher also observed that parents encouraged their children to actively participate in the activities. This 'facilitator' visitor identity is common in informal learning in designed settings, especially in the case of parents (Falk, 2006; Gerber, Cavallo and Marek, 2001), and clearly applies to more everyday leisure environments also. Within this research 'facilitators' included both individuals wanting their offspring to 'learn' from the visit (but not recognising any relationship to their own needs), as well as parents who did feel directly involved, expressing an interest in science themselves, and wanting to encourage a similar interest in their children. Given the leisure locations, it might seem obvious that there would be a large proportion of other visitor identities, especially 'experience seekers' or 'rechargers' present within the sample. However there was little direct evidence of such identities within the generic venue environments, although some participants did take on the 'explorers' role. It is acknowledged that this may have been at least in part due to the shortness of the interviews conducted. Unsurprisingly, given the non-scientific venues and unplanned nature of the interactions there were no selfprofessed 'professional hobbyists' present.

\section{Perceived purpose of the activities}

Participants reported a wide variety of purposes that they perceived for the activities. Aspects relating to education or learning were the most frequently cited reasons $(\mathrm{n}=20 ; 28 \%)$, and this was true across all three venues. Adults tended to state more generalised intentions related to learning (not identifying who was supposed to be doing the learning), whilst three children and one adult specifically referred to themselves as 
learners, and a further two children and one adult specifically described 'other' people learning, making less connection to their own involvement in that process:

To kind of like help you with your learning, education and to like help children that may not have the chance to do experiments like these. (HGF9, female child)

I like to think it was to educate people, but I don't think I know. (LF4, male adult)

For me it was the idea that it is ok not to know about science; to have a place and chance to learn about it. (LF14, female adult)

The latter two respondents here demonstrated some of the uncertainty and/or novelty of finding scientific activities at such generic venues. LF4 supported the concept of intending to educate the audience, but was unsure as to whether that was likely to be the intention, given the informality of the music festival environment. For LF14 the interaction was more profound and personal: being less confident in her scientific knowledge she would normally have avoided specifically scientific interactions. However, her chance interaction with the activities, and particularly their welcoming, informal and non-judgmental nature, provided her with an opportunity to further explore such concepts. For participants such as LF14 the generic venues proved to offer good success in achieving the goals of informal science learning.

A further strong purpose that emerged from the interviews was the intention to engage people - particularly children - with science $(n=19,27 \%$ for engagement generally; $\mathrm{n}=13,18 \%$ for children specifically). This assumption relating to children as the target audience was particularly prevalent at HGF, which is perhaps not surprising given the high proportion of family visitors to that venue. According to the participants, 'engagement' (as distinct from 'learning' above) was more about heightening levels of interest, providing stimulation and/or inspiration, and 'making the little ones more aware 
of physics, how the world goes around, etc' (HGF3, female adult). The intentions of the engagement (from the participants' perspectives) were therefore primarily a one-way form of communication, as opposed to 'mutual learning' (McCallie et al., 2009:12) and other definitions of public engagement that exist within the academic field. As noted elsewhere, although the rhetoric within the field of science communication may have moved towards dialogic or consultation-based interactions, publics do not always prioritise or even conceptualise such roles for themselves (Ipsos MORI, 2011; Wilkinson, Dawson and Bultitude, in press).

The combination of science with an element of fun or entertainment was also seen by participants as a specific intention of the activities $(n=12 ; 17 \%)$. These associations occurred across all three venues, for both adults and children. Ten of these respondents linked fun directly with the science learning or educational aspects, with three specifically mentioning that they (and/or other participants) would not normally associate the two together. Whilst participants found the combination of fun with science and learning unexpected, the benefits of this approach have been reported previously in work in science centres where fun is seen not as an optional extra but 'as a virtue intrinsic to the unique type of learning offered by science centres' (Tlili, 2008:317). Hence although it was seen as a novelty by the participants, combining affective enjoyment with scientific content was certainly not a barrier to its likely success. At the other extreme, two respondents (both from HGF) thought that the purpose of the activities was entirely related to entertainment, demonstrating that for those participants at least the events fitted in well with the leisure environment in which they were situated. 
Some participants felt that the activities were designed to overcome some form of deficit, be it how specific subjects (such as physics) are normally perceived by public groups, or encouraging young people into scientific careers:

To make physics more approachable for the general public. Because people think physics is something like nuclear reactor and stuff, crazy scientists... (HGF8, male adult)

The more people get a basic interest perhaps the more people study it which is great for the UK in general. (LF20, male adult)

Probably to get more children interested in physics, "cause there are not many girls in to physics. (HGF4, male adult)

The lack of sufficient appropriately skilled scientists (of both genders) has been recognised as an issue of fundamental concern by the European Commission (EC, 2004) and as noted above some participants demonstrated an awareness of the lack of people taking science degrees. However, two of the four participants who expressed this perspective had a science background themselves, or family and friends in science careers, and another acknowledged a personal interest in science. These respondents are therefore likely to have been previously aware of issues within the sector, hence the alignment of their responses with those stated by funding bodies and governmental organisations is not surprising.

Finally, four participants recognised that these activities were likely to reach people that would not normally engage with such topics. For example, one participant felt that the activities at LF were designed to 'introduce this technology to a wider audience that wouldn't normally come across it' (LF9, female adult). Other participants at LF also 
commented on both the novelty and appropriate match of the activities to the atmosphere of the festival:

...when you stimulate your mind with art, ideas, I think that is the spirit of the festival. So it fits in quite nicely. (LF8, male adult)

I was rather surprised to find it [science activities] here, I didn't expect it to be here. ... I think it is very important to communicate science in a simple and direct way and I think this is a very good example of that. (LF3,male adult)

These perspectives emphasise the importance of not only selecting an appropriate generic venue, but also ensuring that the content of the activities and the mode of delivery are well suited to the leisure environment itself. Novelty alone is insufficient: the quality and appropriateness of the science communication must also be taken into consideration.

The aforementioned purposes of the events as identified by the participants themselves generally relate well to recognised features of informal learning (see for example Bell et al., 2009; McCallie et al., 2009; Packer, 2006). This close overlap between public and governmental / institutional terminology reflects a relatively high degree of awareness within the participant sample of wider social issues and/or government agendas. In some cases the selected terminology may also indicate a form of 'othering' taking place; participants recognised the activities as having intrinsic educational (or entertainment etc.) values, however occasionally (and somewhat paternalistically) saw those benefits applying to other people rather than themselves.

Taking the comparison one step further, from informal science learning to science communication more broadly, the main purposes identified by the participants tended to fall under the 'economic' and 'utilitarian' arguments (Osborne, 2000; Stocklmayer and Bryant, 2011). None of the participants referred to science as a 'cultural' construct, or 
considered the interactions from the perspectives of the scientists involved (related to the 'social' argument). These latter omissions are perhaps unsurprising, being likely to require a broad perspective on the topic and a deeper level of reflection that may not have been possible during the short interviews conducted within this research. However, it is surprising that not one of the interviewees raised aspects relating to the 'democratic' argument - they did not report seeing themselves (nor other participants) as contributing to wider decisions on public issues related to science. These data were collected during a period of increased emphasis and government expenditure on public consultations within the UK - £2.2 million through the Sciencewise-ERC programme alone in 2008/09 (Warburton, 2011). However, the participants' apparent lack of recognition of their own role in such processes serves to indicate that there is still plenty of room for further public mobilisation in this area.

\section{Identified elements of success}

By correlating the results across all three generic venues it is possible to identify three key common factors which contributed to their success: the relaxed and informal atmosphere of each venue; the involvement of scientific experts; and the opportunity for participants to re-engage with scientific concepts outside formal education.

Informality of surroundings: The chosen locations were all places where members of the public felt relaxed, with no normal associations to scientific activities. Additionally, they were very much venues that the participants had actively chosen to visit, where they entered a leisure 'state of mind' as described previously (Edginton and Chen, 2008). As 
with similar events at other 'generic venues' (see for example Brehaut and Simonsson, 2006; Bultitude and Grant, 2005; Ward et al., 2008), this atmosphere of friendliness, informality and relaxation was an important factor in the success of the activities, contributing to building the confidence of the participants as well as ensuring a positive attitude towards becoming involved. Observations of the audiences throughout the different events noted that participants generally looked relaxed and appeared confident enough to actively participate, engage with the scientists/presenters and ask questions.

'Real' scientists: In the three case studies investigated here, the presence of what the audience described as 'real' scientists - people they perceived as experts in the field, with good knowledge and interesting content to share - was also deemed an important success factor:

I just like [it] because everyone knows what they are doing and they can pass all the information to you, whereas if you were out with your family, no one would know this much. (ACE6, female child)

The ordinary guy from the street can understand ... It was really good to actually be able to talk to the speakers afterwards. (LF24, male adult)

Rather than finding the scientists intimidating or remote, both adults and children felt able to talk to the scientists, and as noted by LF24, felt that the individual interaction was an important contributing factor to their enjoyment of the activities. Participants also mentioned how simple and uncomplicated they found the science that was presented; such clarity and ease of interaction with the scientists generally came as a surprise to the participants, in line with other similar previous work (Koolstra, 2008; Ward et al., 2008). The benefits of involving 'real' scientists were therefore both content-oriented as well as 
furthering the novelty and element of surprise in finding such interactions in a leisure location.

Opportunity to re-engage participants outside formal education: As highlighted at the outset of this article, one of the key arguments for hosting events at generic venues is to access otherwise disengaged participants outside of the formal learning environment. Within the three venues investigated here there was evidence of some success in reengaging such audiences. Many adults referred specifically to the activities providing an opportunity to re-visit subjects they had not considered for some time, or inspiring their own learning potential:

Generally, in everyday life you would think about it [science], we all went to school, we all know bits about it, and it's a reminder when you come to places like this: 'yes, it's interesting' (HGF29, adult male)

I was never very good at it at school but he impresses me with his knowledge of it and I think 'well, I wish I knew as much as he did' (HGF31, female adult)

Such comments were particularly prevalent at HGF, where participants tended to be less naturally inclined towards scientific topics. In addition to the increased interest and inspiration mentioned by these adults, some children also reported that the generic venue activities caused them to reconsider their personal interest in scientific concepts: 'I didn't like it [science], but now I see it's interesting' (HGF25, female child). Additionally, there was evidence of a need to support increased desires for learning (including specifically about science) outside the formal education system due to changing interests as individuals get older:

I love science and I'm starting to read more and more as I get older. When I was little it was dead boring, but now I'm more into it. (LF21, female adult) 
Given the relatively short duration of their interaction with the activities, it would no doubt be unrealistic to expect these participants to overtly express an intention to extend this increased interest to changing their behaviour or broader attitudes. However, by providing an opportunity for these individuals to further explore their growing interest in a comfortable and non-threatening environment, the likelihood is much greater that their interest will continue to develop.

\section{Conclusions}

This work has demonstrated that 'generic venues' offer a good opportunity to reach otherwise uninterested audiences with scientific concepts. The interface between the 'everyday' and 'designed' settings for informal science learning (Bell et al., 2009) has been specifically explored in order to further our understanding of the impact of location on the types of audiences that are recruited.

The results demonstrate that holding activities within a relaxed but not habitual environment, where participants are at their leisure, offers clear advantages in reaching non-standard audiences. Whilst some participants made a deliberate effort to attend the activities, over two-thirds appear to have become unexpectedly involved. Participants were attracted to the activities for a wide variety of reasons, including the novel and unexpected presence of the activities themselves, although some participants emphasised the need for the activities to fit in with the environment in which they were presented. As with other informal science learning environments, visual or aural elements and the presence of a crowd were also contributing factors. The scientific content was seen as an additional 'hook' to attract around 1 in 5 participants, who represented a range of ages, 
genders and levels of existing interest in science. This suggests that although they may not be actively seeking engagement with scientific topics, the overt nature of the subject choice is not a significant barrier to audience engagement - for these participants at least. Furthermore, learning or educational outcomes were the most common perceived purpose for the activities, although again this did not appear to discourage involvement.

Activities in well-populated locations that formed part of a wider leisure experience (for example a music festival or a family event) were particularly successful at attracting 'new' audiences. The generic venues also succeeded in recruiting participants who professed to be either neutral or actively antagonistic towards science, although in line with similar evidence of attitudes within the wider UK population, these people were in the minority (RCUK/DIUS, 2008).

Three key aspects were identified as crucial to the success of a science-related activity in a generic venue: the informal and relaxed atmosphere of the location in which it was held; the involvement of people perceived as experts in the subject matter involved; and the provision of opportunities to re-engage participants outside of the formal education context. These insights will assist in the planning and delivery of successful science communication activities in generic locations in future.

\section{Acknowledgements}

The authors would like to express their gratitude to $\square$ [names removed in order to retain anonymity] for their reviews and comments on early versions of this paper. The anonymous reviewers also provided very useful advice and input during the review process, for which we thank them. The work was partially supported by [affiliation removed in order to retain anonymity] though a Post-Doctoral research grant attributed to $\square$ [name removed in order to retain anonymity] (reference $\square$ [removed in order to retain anonymity]). 


\section{References}

Allen, S. (2008) in Friedman, A. (Ed.). Framework for Evaluating Impacts of Informal Science Education Projects. Available from http://caise.insci.org/uploads/docs/Eval_Framework.pdf

Arcand, K. and Watzke, M. (2010) Bringing the universe to the street. A preliminary look at informal learning implications for a large-scale non-traditional science outreach project. Journal of Science Communication 9(2).

Banks, J.A., Au, K., Ball, A., Bell, P., Gordon, E., Gutierrez, K., Brice Heath, S., Lee, C., Lee, Y., Mahiri, J., Nasir, N., Valdes, G. and Zhou, M. (2007). Learning in and out of school in diverse environments. The LIFE Center (The Learning in Informal and Formal Environments Center) and the Center for Multicultural Education, University of Washington, Seattle.

Bazeley, P. (2009) Analysing Qualitative Data: More Than 'Identifying Themes'. Malaysian Journal of Qualitative Research 2: 6-22.

Bell, P., Lewenstein, B., Shouse, A. W. and Feder, M. A. (Eds) (2009) Learning science in informal environments: People, places, and pursuits. Washington, DC: The National Academy Press.

Bentley, M.E., Boot, M.T., Gittelsohn, J. and Stallings, R.Y. (1994) The Use of Structured Observations in the Study of Health Behaviour. Occasional Paper 27. IRC International Water and Sanitation Centre The Hague, The Netherlands.

Brehaut, J. and Simonsson, E. (2006) Dana Centre audience profile: November 2005-July 2006. London: Science Museum.

Bull, C., Hoose, J. and Weed, M. (2003) An Introduction to Leisure Studies. London: Pearson Education.

Bultitude, K. and Grant, L. (2005) Einstein at Glastonbury: Final Report. Bristol: University of the West of England.

Cherryman, S.J., King, S., Hawkes, F.R., Dinsdale, R. and Hawkes, D.L. (2008) An exploratory study of public opinions on the use of hydrogen energy in Wales. Public Understanding of Science 17(3): 397-410.

Dabney, K.P., Tai, R.H., Almarode, J.T., Miller-Friedmann, J.L., Sonnert, G., Sadler, P.M. and Hazari, Z. (in press). Out-of-School Time Science Activities and Their Association with Career Interest in STEM International Journal of Science Education: Part B. DOI:10.1080/21548455.2011.629455.

David, M. and Sutton, C.D. (2004) Social Research - The Basics. SAGE, ${ }^{\text {st }}$ Edition.

DeWitt, J. (2009) Snapshot Interviews. Poster presentation at the ECSITE Annual Conference (4-6 June 2009), Budapest, Hungary. Available from http://www.raeng.org.uk/societygov/public_engagement/ingenious/pdf/JED_poste r_ECSITE09.pdf

EC (European Communities) (2004) Europe needs more scientists: Increasing Human Resources for Science and Technology in Europe. Report of the High Level Group on Human Resources for Science and Technology in Europe. Luxembourg: Office for Official Publications of the European Communities. ISBN 92-894-8458-6.

Edginton, C. and Chen, P. (2008) Leisure as Transformation. Champaign, Illinois: Sagamore Publishing, L.L.C.

EUSCEA (2008) EUSCEA in short, Göteborg, Sweden: EUSCEA. 
Falk, J. H., Donovan, E., and Woods, R. (Eds.). (2001). Free-choice science education: How we learn science outside of school. New York: Teachers College Press.

Falk, J.H. (2006) An Identity-Centered Approach to Understanding Museum Learning Curator 49 (2): 151-66.

Falk, J.H., Storksdieck, M. and Dierking, L.D. (2007) Investigating public science interest and understanding: evidence for the importance of free-choice learning. Public Understanding of Science 16(4): 455-469.

Falk, J.H. and Dierking, L.D. (2010) The 95 Percent Solution. American Scientist 98: 486-493.

Gauchat, G. (in press) The cultural authority of science: Public trust and acceptance of organized science. Public Understanding of Science. doi:

10.1177/0963662510365246

Gerber, B.L., Cavallo, A.M.L. and Marek, E.A. (2001) Relationships among informal learning environments, teaching procedures and scientific reasoning ability. International Journal of Science Education 23(5): 535-49.

Grand, A. (2009) Engaging through dialogue: International experiences of café scientifique, in Holliman, R., Thomas, J., Smidt, S., Scanlon, E. and Whitelegg, E. (eds.) Practising science communication in the information age: Theorising professional practices. Oxford University Press: Oxford.

Ipsos MORI (2011) Public Attitudes to Science - Main Report May 2011. London: Department for Business, Innovation and Skills.

Johnson, B. and Burnet, F. (2000) A route to better understanding. Science Public Affairs. October 2000: 16-17.

Johnson, B., Burnet, F. and Pichler, J. (2003) Science on the Buses: Report to the European Commission. Bristol: University of the West of England.

Koolstra, C.M. (2008) An example of a science communication evaluation study: Discovery07, a Dutch science party. Journal of Science Communication 7(2).

MacDonald, S. (2004) Exhibitions and the Public Understanding of Science Paradox [online]. The Pantaneto Forum, Issue 13. ISSN 1741-1572.

McCallie, E., Bell, L., Lohwater, T., Falk, J. H., Lehr, J. L., Lewenstein, B. V., Needham, C. and Wiehe, B. (2009) Many Experts, Many Audiences: Public Engagement with Science and Informal Science Education. A CAISE Inquiry Group Report. Washington, Center for Advancement of Informal Science Education (CAISE).

Naylor, S. and Keogh, B. (1999) Science on the Underground: an initial evaluation. Public Understanding of Science 8(2): 105-122.

Osborne, J. and Dillon, J. (2007) Research on Learning in Informal Contexts: Advancing the field? International Journal of Science Education 29(12): 1441-1445.

Osborne, J. (2000) Science for Citizenship. In Monk, M. and Osborne, J. (Eds.) Good Practice in Science Teaching: What Research Has to Say. London: Open University Press.

Packer, J. (2006) Learning for Fun: The Unique Contribution of Educational Leisure Experiences. Curator 49(3): 329-44.

Powell, M. and Kleinman, D.L. (2008) Building citizen capacities for participation in nanotechnology decision-making: the democratic virtues of the consensus conference model. Public Understanding of Science 17(3): 329-348. 
RCUK/DIUS (2008). Public Attitudes to Science. A survey. Available from http://www.rcuk.ac.uk/documents/scisoc/pas08.pdf

Rennie, L. (2011) Science Communication and Engagement Beyond Schooling International Journal of Science Education: Part B 1(1): 13-14.

Ritchie, J. and Spencer, L. (1994) Qualitative data analysis for applied policy research. In A. Bryman \& R. G. Burgess (Eds.) Analysing Qualitative Data London: Routledge.

Rowe, G. and Frewer, L. J. (2000) Public participation methods: A framework for evaluation. Science, Technology and Human Values, 25(1): 3-29.

Schibeci, R. and Harwood, J. (2007) Stimulating authentic community involvement in biotechnology policy in Australia. Public Understanding of Science 16(2): 245255.

Schugurensky, D. (2000) The forms of informal learning: towards a conceptualization of the field. WALL Working Paper No.19.

Sosniak, L. (2001) The 9\% Challenge: Education in School and Society. Teachers College Record ID Number: 10756.

Stocklmayer, S. and Bryant, C. (2011) Science and the public - what should people know? International Journal of Science Education: Part B, iFirst Article.

Tlili, A. (2008). The organisational identity of science centres. Culture and Organization 14(4): 309-323.

Tong, A., Sainsbury, P. and Craig, J. (2007) Consolidated criteria for reporting qualitative research (COREQ): a 32-item checklist for interviews and focus groups. International Journal of Quality in Health Care, 19(6): 349-357.

Warburton, D. (2011). Evaluation of Sciencewise-ERC-Final Report. Shared Practice.

Ward, V., Howdle, P. and Hamer, S. (2008) You \& your body: A case study of bioscience communication at the University of Leeds. Science Communication 30(2): 177208.

Wilkinson, C., Dawson, E. and Bultitude, K. (in press) 'Younger People Have Like More of an Imagination, No Offence': Participant Perspectives on Public Engagement International Journal of Science Education: Part B.

DOI:10.1080/21548455.2011.628503. 